\title{
Presynaptic Type III Neuregulin 1 Is Required for Sustained Enhancement of Hippocampal Transmission by Nicotine and for Axonal Targeting of $\alpha 7$ Nicotinic Acetylcholine Receptors
}

\author{
Chongbo Zhong, ${ }^{1}$ Chuang Du, ${ }^{1}$ Melissa Hancock, ${ }^{2}$ Marjolijn Mertz, ${ }^{1,4}$ David A. Talmage, ${ }^{3}$ and Lorna W. Role ${ }^{1,2}$ \\ ${ }^{1}$ Department of Neurosciences and ${ }^{2}$ Integrated Program in Cellular, Molecular, and Biophysical Studies, Columbia University, New York, New York 10032, \\ 3.Department of Pharmacology and Center for Brain and Spinal Cord Research, Stony Brook University, Stony Brook, New York 11794, and ${ }^{4}$ Department of \\ Experimental Neurophysiology, Vrije Universiteit, $1081 \mathrm{HV}$ Amsterdam, The Netherlands
}

\begin{abstract}
Both the neuregulin 1 (Nrg1) and $\alpha 7$ nicotinic acetylcholine receptor $\left(\alpha 7^{\star}\right.$ nAChRs) genes have been linked to schizophrenia and associated sensory-motor gating deficits. The prominence of nicotine addiction in schizophrenic patients is reflected in the normalization of gating deficits by nicotine self-administration. To assess the role of presynaptic type III Nrg1 at hippocampal-accumbens synapses, an important relay in sensory-motor gating, we developed a specialized preparation of chimeric circuits in vitro. Synaptic relays from $N r g 1^{\text {tmlLwr }}$ heterozygote ventral hippocampal slices to wild-type (WT) nucleus accumbens neurons (1) lack a sustained, $\alpha 7^{\star}$ nAChRsmediated phase of synaptic potentiation seen in comparable WT/WT circuits and (2) are deficient in targeting $\alpha 7^{\star} n A C h R s ~ t o ~ p r e s y n a p t i c$ sites. Thus, selective alteration of the level of presynaptic type III Nrg1 dramatically affects the modulation of glutamatergic transmission at ventral hippocampal to nucleus accumbens synapses.
\end{abstract}

Key words: neuregulin 1; $\alpha 7$ nicotinic acetylcholine receptor; sensory-motor gating; ventral hippocampal-nucleus accumbens synapses; schizophrenia; synaptic plasticity

\section{Introduction}

Neuregulin 1 (Nrg1)-ErbB signaling regulates synapse formation, synaptic plasticity, and the maintenance of synaptic connections, in part by regulating the levels of functional neurotransmitter receptors (Yang et al., 1998; Huang et al., 2000; Wolpowitz et al., 2000; Liu et al., 2001; Kawai et al., 2002; Falls, 2003; Okada and Corfas, 2004; Gu et al., 2005; Kwon et al., 2005; Chang and Fischbach, 2006; Bjarnadottir et al., 2007; Li et al., 2007). The implication of $\mathrm{Nrg} 1$ as a schizophrenia susceptibility gene underscores the importance of understanding the relationship between $\mathrm{Nrg} 1$ signaling and circuits affected in schizophrenia (Stefansson et al., 2004; Harrison and Weinberger, 2005).

The majority of patients with schizophrenia are heavy smokers, consistent with proposed roles of nicotine as a form of selfmedication (Batel, 2000; Kumari and Postma, 2005; Strand and

Received Jan. 28, 2008; revised June 30, 2008; accepted July 1, 2008.

This work was funded by Grants NS29071 and DA019941 from National Alliance for Research on Schizophrenia and Depression (Sidney Baer Distinguished Investigator Award to L.W.R.) and the McKnight Foundation (L.W.R.) M.H. was supported by National Institutes of Health Grant T32 DK07328. We thank Drs. S. Siegelbaum, Y. H. Jo, and M. Johnson for suggestions on previous versions of this manuscript.

${ }^{*}$ C.Z. and C.D. contributed equally to this work.

Correspondence should be addressed to Lorna W. Role at her present address: Department of Neurobiology and Behavior, Stony Brook University, Stony Brook, NY 11794. E-mail: Iorna.role@stonybrook.edu.

C. Du's present address: Center for Neuroscience Research, Tufts University School of Medicine, 136 Harrison Avenue, Boston, MA 02111.

C. Zhong's, M. Hancock's, M. Mertz's, and L. W. Role's present address: Department of Neurobiology and Behavior and Center for Brain and Spinal Cord Research, Stony Brook University, Stony Brook, NY 11794.

DOI:10.1523/JNEUROSCI.0381-08.2008

Copyright $\odot 2008$ Society for Neuroscience $\quad$ 0270-6474/08/289111-06\$15.00/0
Nybäck, 2005). Nrg1-ErbB signaling has been implicated in the regulation of neuronal nicotinic acetylcholine receptors (nAChR), in particular the $\alpha 7^{\star}$ nAChRs (Yang et al., 1998; Liu et al., 2001; Kawai et al., 2002; Chang and Fischbach, 2006; Mathew et al., 2007; Hancock et al., 2008), renowned for their role in nicotine-induced plasticity of corticolimbic and mesolimbic circuits (McGehee et al., 1995; Dajas-Bailador and Wonnacott, 2004; Jo et al., 2005; Mansvelder et al., 2006; Couey et al., 2007). Because genetic studies have linked both the $\mathrm{Nrg} 1$ and $\alpha 7$ subunit genes to major endophenotypes of schizophrenia (Leonard et al., 1998; Harrison and Weinberger, 2005; Mathew et al., 2007), we tested whether reduced expression of type III Nrg1 alters nicotine responsiveness in the ventral striatum, specifically in the nucleus accumbens shell (nAcc), in which convergent inputs from prefrontal cortex, ventral hippocampus/subiculum (vHipp), ventral tegmental area, and amygdala are integrated to produce contextinformed volitional behaviors (Lisman and Grace, 2005; Ronesi and Lovinger, 2005). We demonstrate that presynaptic type III $\mathrm{Nrg} 1$ determines normal levels of presynaptic targeting of $\alpha 7^{*}$ nAChRs along axons of ventral hippocampal neurons.

\section{Materials and Methods}

Genotype-specific vHipp-nAcc synaptic cocultures. Animals were treated in accordance with the National Institutes of Health Guide for the Care and Use of Laboratory Animals. The region of ventral CA1 and subiculum of hippocampi from single wild-type (WT) animals or animals heterozygous for an isoform-specific disruption of type III Nrg1 $\left(\mathrm{Nrg}^{\text {tm } 1 \mathrm{Lw}}+/-\right)$ (Wolpowitz et al., 2000) were sliced into $150 \times 150 \mu \mathrm{m}$ pieces and plated in minimal volume of culture media $(50 \mu \mathrm{l})$. Dispersed WT nAcc neu- 
rons (embryonic day 16 to postnatal day 1 ) were added after the vHipp explants had attached. Additional details of the specialized technique developed for these studies can be found in the legend of Figure 1 and in supplemental data (available at www.jneurosci.org as supplemental material).

Immunostaining and fluorescent visualization. For $\alpha$-bungarotoxin $(\alpha \mathrm{BgTx})$ labeling, the coverslips were incubated with $\alpha$ BgTx conjugated to Alexa 594 (1:1000; Invitrogen) for 30 $\min$ at $37^{\circ} \mathrm{C}$ before fixation. For standard immunodetection, coverslips were fixed in $4 \%$ paraformaldehyde/4\% sucrose/PBS (20 min, $4^{\circ} \mathrm{C}$ ), treated with $0.25 \%$ Triton X-100/PBS (5 $\mathrm{min}$ at room temperature) and $10 \%$ preimmune donkey serum in PBS (30 min at room temperature), and then incubated in primary antibody for $2 \mathrm{~h}$ and secondary antibody for $1 \mathrm{~h}$ at $37^{\circ} \mathrm{C}$. Antibodies used included the following: anti-vesicular glutamate transporter 1 (vGluT1) 1:250; Synaptic Systems), antiGAD65 (1:50; Developmental Studies Hybridoma Bank), and FITC- and rhodamineconjugated Ig (1:150 to 1:200; Jackson ImmunoResearch). $\alpha$ BgTx clusters (defined as six contiguous pixels at $50 \%$ of maximal intensity) were quantified using a custom algorithm with MetaMorph software (version 7.1; Molecular Devices).

Electrophysiological recordings. Macroscopic and synaptic currents were recorded by wholecell configuration of the patch-clamp technique, with cells held at $-60 \mathrm{mV}$. Preparations were continuously perfused with extracellular solution containing the following (in mM): 145 $\mathrm{NaCl}, 3 \mathrm{KCl}, 2.5 \mathrm{CaCl}_{2}, 10$ HEPES, and 10 glucose, $\mathrm{pH}$ 7.4. The intracellular solution included the following (in mM): $3 \mathrm{NaCl}, 150 \mathrm{KCl}$, $1 \mathrm{MgCl}_{2}, 1$ EGTA, 10 HEPES, $5 \mathrm{MgATP}$, and 0.3 NaGTP, pH 7.2. Voltage-clamp recordings were performed with a List EPC-7 Patch Clamp Amplifier (Medical Systems). CNQX, AP-5, bicuculline (Tocris Cookson), $\alpha \mathrm{BgTx}$, and TTX (Sigma) were included in the perfusate as noted. (-)-Nicotine (hydrogen tartrate salt) and glutamate were applied via local pressure ejection (Picospritzer; General Valve).

Data collection and statistical analysis. Macroscopic and synaptic currents were filtered at $10 \mathrm{kHz}$ with a eight-pole Bessel filter (direct current amplifier/filter; Warner Instruments) before acquisition and digitization through a DigiData 1200B analog-to-digital interface with pClamp8 (Molecular Devices). Peaks of macroscopic currents were determined by pClamp8 (Fetchan), and decay time constants were calculated with Origin; Microcal Software). Spontaneous synaptic currents, amplitude, rise time, half-decay time, and frequency of miniature EPSCs (mEPSCs) were measured with MiniAnalysis (Synaptosoft). Normally distributed data were assessed for statistical significance by ANOVA with a post hoc test for multiple comparisons and group means with unequal sample size. Nonnormally distributed data were analyzed using nonparametric methods (Kolmogorov-Smirnov test).

\section{Results}

\section{Gene chimeric synapses}

We developed a specialized preparation of hippocampal-striatal circuits in vitro to study the effects of genetic manipulation of presynaptic neurons in mouse CNS synapses (Fig. 1). vHipp and subicular regions were extirpated from WT or $\mathrm{Nrg}^{\text {tm1Lwr }}+/-$ mice (Fig. 1A). Microexplants were plated in minimal volume and allowed to spread [WT (Fig. 1C, c1), +/- (Fig. 1D, d1)] before the addition of dispersed target neurons from the nucleus accumbens shell (Fig. $1 B$ ). We focused our analysis on the role of type III Nrg1 in the presynaptic vHipp projections in regulating plasticity at hippocampal-striatal synapses by keeping the nAcc genotype (WT) constant and varying the genotype of the vHipp slices.

The general features of chimeric $N r g 1^{\text {tm1Lwr }}+/$ - preparations were indistinguishable from those of sibling cocultures from WT mice. The overall profile of hippocampal glutamatergic fiber outgrowth (vGluT ${ }^{+}$fibers), the number of vGluT ${ }^{+}$puncta along vHipp axons, the survival of nAcc neurons $\left(\mathrm{GAD} 65^{+}\right)$, and the percentage of $\mathrm{nAcc}$ neurons that received synaptic input within 1 week were found to be independent of the presynaptic genotype (Fig. $1 E-G$ ).

Patch-clamp recording from contacted WT nAcc neurons after 4-7 d in vitro revealed ongoing glutamatergic (microslicederived) and GABAergic (nAcc to nAcc) synaptic activity, 


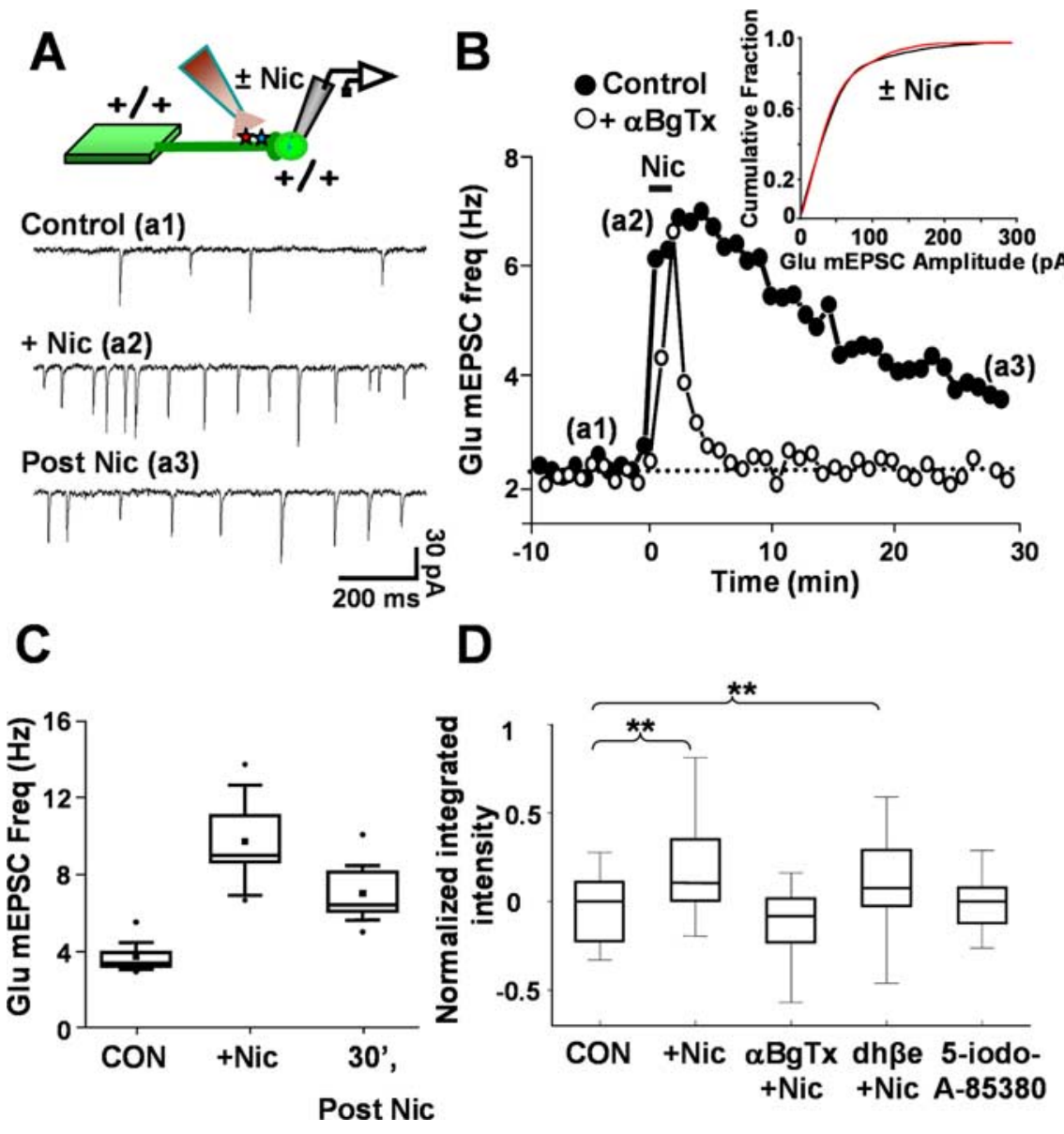

Figure 2. A single application of nicotine elicits a sustained enhancement of transmission at WT vHipp/WT nAcc synapses. $A$, Top, Schematic diagram of the recording configuration used for nicotinic modulation of glutamatergic transmission. a1, Control profile of spontaneous glutamate-receptor-mediated synaptic activity (Glu mEPSCs: bicuculline and TTX resistant; CNQX-APV sensitive). $\boldsymbol{a} 2$, Spontaneous synaptic currents with nicotine ( $+\mathrm{Nic}$ ) recorded in the same $n$ Acc neuron $\sim 2$ min after application and washout of nicotine (500 nм; $1 \mathrm{~min}$ ). $\mathbf{a} 3$, Postnicotine records obtained $\sim 30 \mathrm{~min}$ after 1 min nicotine application and washout. $\boldsymbol{B}$, Glu mEPSC frequency (in hertz) versus recording time (in minutes). Note that the nicotine-evoked enhancement of $\mathrm{mEPSC}$ frequency occurs without change in $\mathrm{mEPSC}$ amplitude (inset in $\boldsymbol{B}$ : control, black; with nicotine, red, sampled at 5 min before, during, and immediately after $\boldsymbol{a} \mathbf{1}$ and $\boldsymbol{a} \mathbf{2}$ ). The nicotine-evoked increase includes two pharmacologically, temporally distinguishable phases. The early/acute phase of nicotine-enhanced transmission was resistant to the $\alpha 7^{*} \mathrm{nAChRs}$-selective antagonist $\alpha \mathrm{BgTx}$ (filled circles, \pm Nic at $t=0$; open circles, $+\alpha \mathrm{BgTx}$ ). In addition, a sustained enhancement of Glu mEPSCs lasting $>30$ min after nicotine application was seen at this and at all nicotine-sensitive WT to WT synapses examined ( $\boldsymbol{B}$, filled circles; $\boldsymbol{C}$. The sustained component was blocked by $\alpha \operatorname{BgTx}$ ( $\boldsymbol{B}$, open circles; $\boldsymbol{C}$ ). $\boldsymbol{C}$, Box plot of results assaying the time course of nicotine-enhanced transmission at WT to WT synapses. The Glu mEPSC frequency over 2 min of recording under the indicated conditions ( $n=8$ for each condition) is plotted in hertz. A Kolmagorov-Smirnov analysis revealed significant increases in Glu $\mathrm{mEPSC}$ frequency in response to a $1 \mathrm{~min}$ nicotine application (CON vs Nic, $p<0.005$ ) that was still evident $30 \mathrm{~min}$ after nicotine addition and washout (CON vs Nic, $30 \mathrm{~h}, p<0.01)$. D, Box plot analysis evaluating the pharmacology of sustained changes in $\left[\mathrm{Ca}^{2+}\right]_{\mathrm{i}}$ at WT fluo-3-loaded vHipp axons. The $\alpha 7^{*} \mathrm{nAChRs}$-selective antagonist $\alpha \mathrm{BgTx}(100 \mathrm{~nm})$ eliminated sustained nicotineinduced increase in $\left[\mathrm{Ca}^{2+}\right]_{i}$, whereas the $(\alpha \beta)^{*}$ AChR antagonist DH $\beta E(1 \mu \mathrm{m})$ did not. 5-lodo-A-85380 $(10 \mu \mathrm{M})$, an $(\alpha \beta)^{*}$ AChR agonist, did not elicit a sustained increase in $\left[\mathrm{Ca}^{2+}\right]_{\mathrm{i}}{ }^{* *} p<0.01$; ANOVA, Holm-Sidak test.

whether the ventral hippocampal slice was derived from WT or from $\mathrm{Nrg} 1^{\text {tmlLwr }}+/-$ mice (see Figs. 1G, 2, 3). Glutamatergic miniature postsynaptic currents (Glu mEPSCs) were recorded in the presence of bicuculline $(20 \mu \mathrm{M})$ and TTX $(2 \mu \mathrm{M})$, and Glu mEPSCs were blocked by application of CNQX $(10 \mu \mathrm{M})$ and APV $(50 \mu \mathrm{M})$.

\section{Sustained enhancement of hippocampal-accumbens} glutamatergic transmission by nicotine Continuous recording of glutamatergic transmission at $+/+$ to $+/+$ synapses during and after a brief exposure to a low concentration of nicotine (1 $\mathrm{min}, 100-500 \mathrm{nM}$ ) revealed a sustained
(>30 min) enhancement of transmission (Fig. 2). The frequency of Glu mEPSCs increased $2.8 \pm 0.3$-fold (from 3-4 to 8-14 $\mathrm{Hz} ; n=8$ ) when nicotine was applied. The initial increase in Glu mEPSC frequency was followed by a sustained, $2.0 \pm 0.1$-fold increase above the pre-nicotine Glu mEPSC frequency (Fig. 2A-C). The nicotine-induced enhancement of glutamatergic synaptic transmission was partially blocked by $\mathrm{nAChR}$ subtype-selective antagonists and completely blocked by general nicotinic antagonists (e.g., mecamylamine; data not shown). Most notably, pretreatment with the $\alpha 7^{\star}$ nAChRs-selective antagonist $\alpha \mathrm{BgTx}$ eliminated the sustained enhancement of glutamatergic transmission but left the transient enhancement of transmission by nicotine intact (Fig. 2B). Brief application of nicotine also resulted in sustained, focal increases in $\left[\mathrm{Ca}^{2+}\right]_{\mathrm{i}}$ along vHipp axons (Fig. 2D) (supplemental Fig. 1, available at www.jneurosci.org as supplemental material). The sustained, nicotine-induced increases in presynaptic $\left[\mathrm{Ca}^{2+}\right]_{i}$ were blocked by $\alpha$ BgTx but not by dihydro- $\beta$ erythroidine (DH $\beta$ E). A non- $\alpha 7 \mathrm{nAChRs}$ agonist (5-Iodo-A-85380) did not elicit a sustained increase in presynaptic $\left[\mathrm{Ca}^{2+}\right]_{\mathrm{i}}$.

Type III Nrg1 chimeric vHipp $\rightarrow$ nAcc synapses lack sustained enhancement of glutamatergic transmission

We next examined the effects of nicotine on glutamatergic transmission at synapses between $\mathrm{Nrg}^{\text {tmlLwr }}+/$ - vHipp and $+/+$ nAcc neurons. The magnitude of the rapid nicotine-induced facilitation detected at chimeric synapses was comparable with that detected at $+/+$ to $+/+$ synapses (Fig. $3 A-C)$. However, at chimeric synapses, the nicotine-induced synaptic facilitation was short-lived (Fig. $3 A-C$ ), returning to control levels immediately after washout of nicotine (Fig. 3B). The nAChR-mediated enhancement of glutamatergic transmission at chimeric synapses was insensitive to the $\alpha 7^{\star}$ nAChRsselective antagonist $\alpha \operatorname{BgTx}$ (Fig. 3B).

The brief nature of the nicotineinduced enhancement of glutamatergic transmission at chimeric synapses was paralleled by a transient, rather than a sustained, increase in presynaptic $\left[\mathrm{Ca}^{2+}\right]_{\mathrm{i}}$ (Fig. 3D). Pooled data summarizing the effect of presynaptic, monoallelic deletion of type III $\mathrm{Nrg} 1$ on the modulation of hippocampal glutamatergic transmission and on presynaptic $\left[\mathrm{Ca}^{2+}\right]_{\mathrm{i}}$ are presented in Figure $3 D$ and supplemental Figure 2 (available at www.jneurosci.org as supplemental material). In chimeric circuits, the sustained, $\alpha$ BgTxsensitive component of nicotine-enhanced transmission was abolished, whereas the transient effects on both glutamate release and $\mathrm{Ca}^{2+}$ signaling were preserved. These data are consistent with a selective loss of functional $\alpha 7^{\star} \mathrm{nAChRs}$ at presynaptic sites 
along $\mathrm{Nrg} 1^{\text {tmlLwr }}+/-$ vHipp axonal projections, without loss of non- $\alpha 7^{\star} n A C h R s$ that support transient responses to nicotine.

Type III Nrg1 back-signaling increases surface expression of $\alpha 7 \mathrm{nAChRs}$ along vHipp axons

To assess whether the loss of $\alpha 7 \mathrm{nAChRs}$ response at type III Nrg1 chimeric synapses was attributable to decreased axonal $\alpha 7 \mathrm{nAChRs}$ expression, we measured $\alpha 7 \mathrm{nAChRs}$ levels in vHipp explants and along vHipp projections. Analysis of hippocampal axons revealed $>70 \%$ decrease in the fraction of $\mathrm{vGluT}^{+}$axons that colabeled with $\alpha \mathrm{BgTx}$ in $\mathrm{Nrgl}^{\text {tmlLwr }}+/-$ vHipp to WT nAcc compared with $+/+$ vHipp to $+/+$ nAcc cocultures (Fig. $4 A, B)$. Total $\alpha 7$ protein levels in vHipp microslices from $\mathrm{Nrgl}^{\text {tm ILwr }}+/-$ mice were $\sim 40 \%$ lower than levels in WT slices (Fig. 4D). These results indicate that WT levels of type III Nrg1 signaling are required for expression of functional presynaptic $\alpha 7^{\star}$ nAChRs.

Type III Nrg1 functions as a bidirectional signaling molecule (Bao et al., 2003; Hancock et al., 2008). To test the possibility that axonal type III Nrg1, acting as a receptor, regulates $\alpha{ }^{\star}$ nAChRs levels along axons, we treated vHipp microslices with the extracellular domain of ErbB4 (B4-ECD, $2 \mathrm{~nm}$ ) for 1, 6, or $24 \mathrm{~h}$. We visualized $\alpha 7^{*}$ nAChRs present on the surface of vHipp axons by staining live preparations with labeled $\alpha \operatorname{BgTx}$ (red) before fixation. When vHipp microslices from $\mathrm{Nrg}^{\text {tmILwr }}+1-$ animals were treated with B4-ECD for 6 or $24 \mathrm{~h}$ (but not after $1 \mathrm{~h}$ ), levels of $\alpha 7^{\star}$ nAChRs clusters at glutamatergic synapses increased from $\sim 12$ per $100 \mu \mathrm{m}$ to $\sim 40$ per $100 \mu \mathrm{m}$ axon length, a level comparable with that seen in $+/+$ microslices (treatment of $+/+$ vHipp microslices with B4-ECD increased the number of $\alpha 7^{*}$ nAChRs clusters from $\sim 30$ clusters $/ 100 \mu \mathrm{m}$ to $\sim 40$ clusters $/ 100 \mu \mathrm{m}$ ) (Fig. $4 B$ ). Microslices from $\mathrm{Nrg}^{\mathrm{I}^{\mathrm{tm} I L w r}-/- \text { an- }}$ imals did not respond to B4-ECD treatment (supplemental Fig. 3D, available at www.jneurosci.org as supplemental material). To determine whether the B4-ECD-

induced increase in $\alpha 7^{*} \mathrm{nAChRs}$ resulted from recruitment of preexisting intracellular pools, we repeated the B4-ECD treatment of $+/+$ and $+/-$ microslices in the presence of cycloheximide (CHX) for $6 \mathrm{~h}$. CHX treatment alone did not affect levels of $\alpha$ BgTx staining but eliminated the B4-ECD-induced increase in $\alpha 7^{*}$ nAChRs levels (Fig. 4C). B4-ECD treatment of vHipp microslices from $\mathrm{Nrg}^{\text {tmiLwr }}+/$ - animals also restored the ability of these neurons to mount a sustained elevation of intracellular calcium in response to brief exposure to nicotine (Fig. 3D). Thus, increased type III Nrg1 back-signaling in Nrg1 $1^{\text {tm } I \text { Lwr }}+/$ - vHipp microslices restored functional axonal $\alpha 7^{\star}$ nAChRs to WT levels.
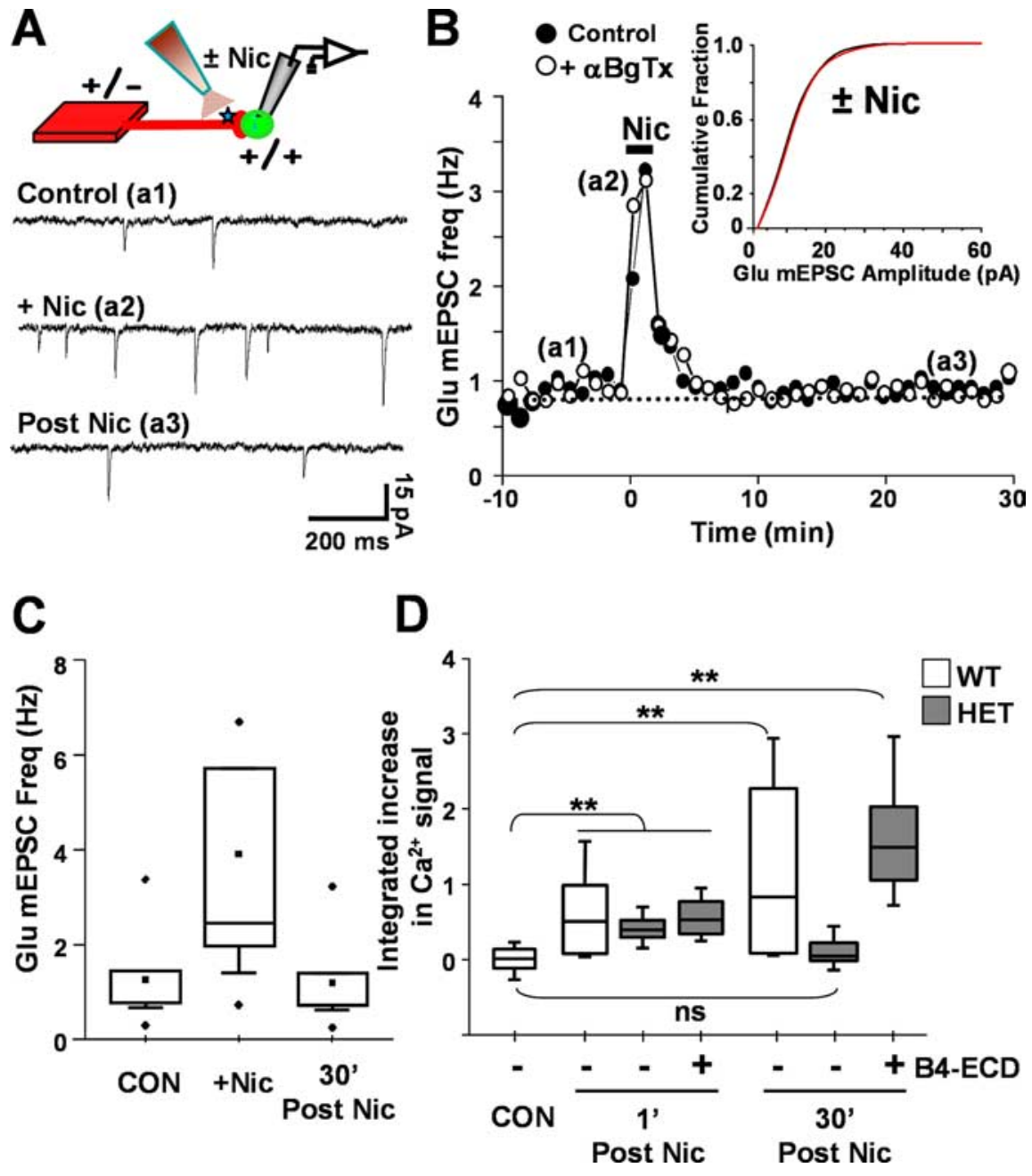

Figure 3. Nicotine enhancement of transmission at Nrg $7^{\text {tm } 1 L w r}+/-v$ Hipp to WT nAcc synapses is brief. $\boldsymbol{A}$, Top, Schematic diagram of the recording configuration in assays of glutamatergic synapses in $+1-$ vHipp slice (red) and dispersed WT nAcc neurons (green). a1, Control Glu mEPSCs (bicuculline and TTX resistant; CNQX-APV sensitive). $\boldsymbol{a} 2$, Spontaneous synaptic currents with nicotine ( $+\mathrm{Nic}$ ) recorded in the same nAcc neurons $\sim 2 \mathrm{~min}$ after application and washout of nicotine ( $500 \mathrm{~nm} ; 1 \mathrm{~min}) . \boldsymbol{a}$, Postnicotine records obtained $\sim 30$ min after a 1 min nicotine application and washout. $\boldsymbol{B}$, In contrast to WT vHipp to WT nAcc transmission, the nicotine-induced enhancement of mEPSC frequency was brief (filled circles) and insensitive to $\alpha$ BgTx (open circles) at $N r g 7^{\text {tm } 7 L w r}+1-$ to WT synapses. Inset in B, There was no effect of nicotine on mEPSC amplitude (control, black; + Nic, red) sampled at 5 min before, during, and immediately after nicotine application $(\boldsymbol{a} \mathbf{1}, \boldsymbol{a} \mathbf{2}$, and $\boldsymbol{a} \mathbf{3}$, respectively). $\boldsymbol{C}$, Box plot of pooled data ( $n=8$ for each condition) examining the time course of modulation of transmission at $\mathrm{Nrg} 1^{\text {tm } 7 \mathrm{Lwr}}+/-$ vHipp to $+1+n$ Acc synapses. Although there were significant effects of nicotine on short-term Glu mEPSC frequency (CON vs Nic, $p<$ 0.01 ), the enhancement of synaptic transmission did not persist (CON vs Nic 30 min; not significant). Note that the fold effect of nicotine on increasing glutamate receptor mEPSCs was comparable, but the baseline mEPSC frequency was typically lower and the nicotine response more variable in $\mathrm{Nrg} 7^{\text {tm } 7 \mathrm{Lwr}}+/-$ to $+/+$ than those recorded in $+/+$ to $+/+$ cocultures. $\boldsymbol{D}$, Box plot of of nicotine on $\left[\mathrm{Ca}^{2+}\right]_{\mathrm{i}}$ were comparable for $+/+$ versus $+/-$ vHipp axons (with or without B4-ECD treatment). In contrast, the sustained increase in calcium signaling seen $\geq 20$ min after nicotine treatment at $+1+$ vHipp axons was not detected in $\mathrm{Nrg} 1^{\text {tm } \mathrm{Lwr}}+/$ - vHipp axons. Incubation with B4-ECD $(24 \mathrm{~h})$ rescued this deficit. ${ }^{* *} p<0.01$. HET, Heterozygous animals.

\section{Discussion}

Using an in vitro microslice preparation that permits examination of CNS synapses comprising genetically distinct presynaptic versus postsynaptic neurons, we demonstrate that type III Nrg1 is required for nicotine-induced sustained potentiation of glutamatergic transmission at hippocampal-accumbens synapses. The persistent phase of glutamatergic facilitation, which lasts up to $1 \mathrm{~h}$ after a single, 1 min exposure to $100 \mathrm{~nm}$ nicotine, is mediated by presynaptic $\alpha 7^{\star}$ nAChRs. Decreased expression of presynaptic type III $\mathrm{Nrg} 1$ results in an $\sim 80 \%$ reduction in functional $\alpha 7^{\star}$ nAChRs on axonal surfaces, as assessed by $\alpha \mathrm{BgTx}$ staining 
A

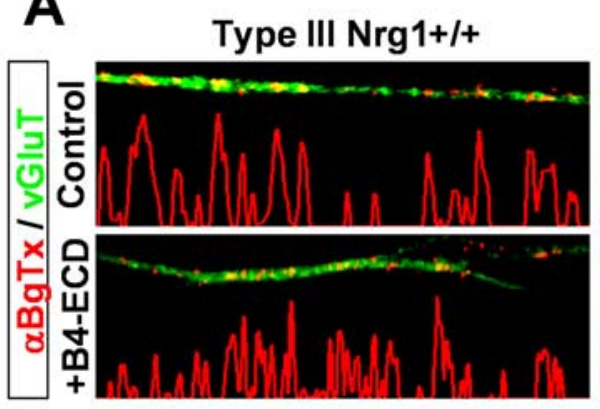

B

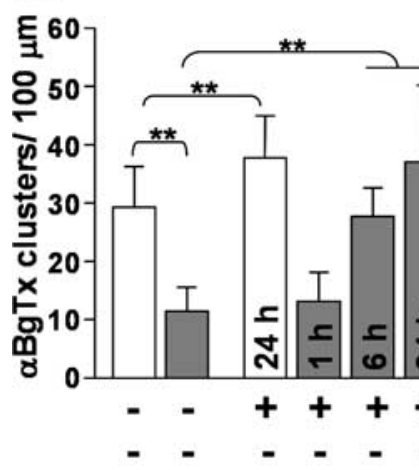

Type III Nrg1+/-

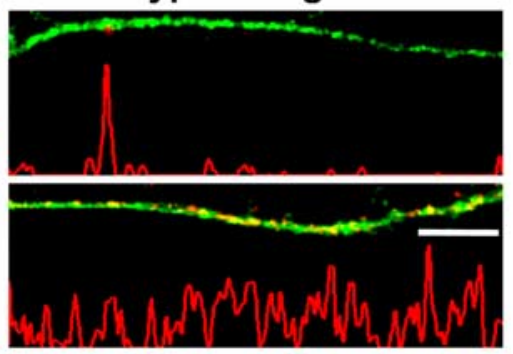

Figure 4. Type III Nrg1 signaling regulates expression of $\alpha 7^{*}$ nAChRs along vHipp axons. $A$, vHipp explants from either $+/+$ or $\mathrm{Nrg}^{\text {tm1Lwr }}+/$ - mice were labeled for surface $\alpha 7^{*} \mathrm{nAChRs}$ with $\alpha \mathrm{BgTx}$-Alexa 594 (red). Cultures were then fixed, permeabilized, and stained with antibodies recognizing vGluT (green). Representative micrographs of WT (left) and Nrg ${ }^{\text {tm } 1 \mathrm{Lwr}}+1-$ (right) vHipp axons are shown above line scans of fluorescence intensity profile for $\alpha \mathrm{BgTx}$ staining. Top, There is a significant decrease in the number of $\alpha \mathrm{BgTx}$-labeled clusters along axons from $\mathrm{Nrg} 1^{\text {tm } 1 \mathrm{Lwr}}+/$ - explants compared with WT (plotted in $\boldsymbol{B}$ ). Bottom, After treatment with B4-ECD, the number of $\alpha$ BgTx-labeled clusters increased along both WT and $\mathrm{Nrg}^{\text {tm }^{\mathrm{m}} \mathrm{Lwr}}+/-$ axons. Magnification, $40 \times$. Scale bar, $5 \mu \mathrm{m}$. B, $\alpha$ BgTx clusters along axons were quantified under control or after 1,6, or $24 \mathrm{~h}$ B4-ECD treatment. The level of surface $\alpha \mathrm{BgTx}$ clusters was lower on Nrg1 ${ }^{\text {tm } 1 \mathrm{Lwr}}+/$ - versus $+/+$ axons $(11.6 \pm 3.9$ vs $29.5 \pm$ 7 clusters $/ 100 \mu \mathrm{m})$. A $24 \mathrm{~h}$ B4-ECD treatment induced a 1.3-fold increase in surface $\alpha B g T x$ clusters along WT vGlut ${ }^{+}$axons: control, $29.5 \pm 7.0$ versus B4-ECD, $38.1 \pm 7.2$ clusters $/ 100 \mu \mathrm{m}$ axon. B4-ECD treatment for 6 or 24 , but not $1 \mathrm{~h}$, increased surface $\alpha$ BgTx staining along Nrg ${ }^{\text {tm 1Lwr }}+/$ - axons: control, $11.6 \pm 3.9$ versus $1 \mathrm{~h} \mathrm{~B} 4-\mathrm{ECD}, 13.1 \pm 6.6 ; 6 \mathrm{~h} \mathrm{~B} 4-\mathrm{ECD}, 28.8 \pm 6.2 ;$ and $24 \mathrm{~h}$ B4-ECD, $37.5 \pm 12.9$ clusters/100 $\mu \mathrm{m}$ axon. In parallel, vHipp microslices were treated with $10 \mu \mathrm{m}$ CHX with and without B4-ECD for $6 \mathrm{~h}$. CHX blocked the B4-ECD-induced increase in $\alpha$ BgTx binding in both $+/+$ and $+/-$ cultures. ${ }^{* *} p<0.01$. C, Total ventral hippocampal $\alpha 7$ protein was measured by immunoblotting. Nrg $1^{\text {tm } 1 L w r}+/-$ vHipp lysate had an $\sim 40 \%$ reduction in total $\alpha 7$ protein compared with WT. HET, Heterozygous animals.

and nicotine-elicited changes in axonal $[\mathrm{Ca}]_{\mathrm{i}}$. Incubation of vHipp microslices with recombinant B4-ECD increased the levels of surface $\alpha 7^{\star}$ nAChRs along glutamatergic projections from WT vHipp microslices and restored levels of surface $\alpha 7^{\star} \mathrm{nAChRs}$ along glutamatergic projections from $+/-$ vHipp microslices. Whether the increase in surface $\alpha 7^{\star} \mathrm{nAChRs}$ reflects a specific effect of ErbB4/Nrg1 signaling on the $\alpha 7$ subunit per se or is secondary to more general response of $\alpha 7^{\star}$ nAChRs-expressing vHipp projection neurons is not clear at this time. We propose that presynaptic type III Nrg1 is required for the normal levels of expression and axonal targeting of $\alpha 7^{\star}$ nAChRs.

Expression and somatodendritic trafficking of $\alpha 7^{\star} \mathrm{nAChRs}$ is regulated by Nrg1/ErbB and neurotrophin/Trk signaling (Yang et al., 1998; Liu et al., 2001; Kawai et al., 2002; Chang and Fischbach, 2006; Massey et al., 2006; Hancock et al., 2008). Our current results are distinct from previous studies in that the requirement for type III Nrg1 is cell autonomous, i.e., presynaptic type III Nrg1 regulates presynaptic $\alpha 7^{\star} n A C h R s$. Type III Nrg1 isoforms have the capacity to participate in bidirectional, juxtacrine signaling that involves both transcriptional responses and local signaling in axons (Bao et al., 2003; Hancock et al., 2008). We propose that the $\alpha 7^{\star} \mathrm{nAChRs}$ is a target of both forward signaling downstream of activated ErbB receptors and reverse signaling. Within the hippocampus, Nrg1/ErbB signaling regulates levels of $\alpha 7^{\star} \mathrm{nAChRs}$ on interneurons (Liu et al., 2001; Chang and Fischbach, 2006). We now demonstrate that type III Nrg1 reverse signaling regulates $\alpha 7^{\star} \mathrm{nAChRs}$ expression and targeting to ventral hippocampal axonal projections. In this manner, Nrg1/ErbB signaling affects cholinergic modulation within hippocampal circuits as well as cholinergic modulation of hippocampal output.

The chimeric in vitro preparation from Nrg1 $1^{\text {tm1Lwr }}$ mice described here provides an informative approach for studying the role of $\mathrm{Nrg} 1$ signaling in both presynaptic and postsynaptic mechanisms of synaptic plasticity. The modulatory influence of ACh on ventral striatal circuits involves both muscarinic and nicotinic receptors, as well as presynaptic and postsynaptic mechanisms (Ge and Dani, 2005; Wang et al., 2006). Current findings support the proposal that genetic modifications of Nrg1-mediated signaling in presynaptic inputs changes the presynaptic profile of nAChRs and thereby alters the temporal profile of responses to nicotine. Alterations in this temporal profile might lead to deficits in sensory gating by altering glutamatergic transmission in corticostriatal circuits (supplemental Fig. 4, available at www.jneurosci.org as supplemental material). In particular, glutamatergic transmission from vHipp to nAcc is thought to be involved in the regulation of sensory gating or prepulse inhibition (PPI), and PPI deficits are a common endophenotype of schizophrenia. Self-administration of nicotine might represent a means of coping with the altered temporal response to nicotine and might underlie the ameliorating effect of nicotine administration on PPI deficits as proposed previously (Bast and Feldon, 2003; Zornoza et al., 2005).

\section{References}

Bao J, Wolpowitz D, Role LW, Talmage DA (2003) Back signaling by the Nrg-1 intracellular domain. J Cell Biol 161:1133-1141.

Bast T, Feldon J (2003) Hippocampal modulation of sensorimotor processes. Prog Neurobiol 70:319-345.

Batel P (2000) Addiction and schizophrenia. Eur Psychiatry 15:115-122.

Bjarnadottir M, Misner DL, Haverfield-Gross S, Bruun S, Helgason VG, Stefansson H, Sigmundsson A, Firth DR, Nielsen B, Stefansdottir R, Novak TJ, Stefansson K, Gurney ME, Andresson T (2007) Neuregulin1 (NRG1) signaling through Fyn modulates NMDA receptor phosphorylation: differential synaptic function in NRG1 ${ }^{+/-}$knock-outs compared with wild-type mice. J Neurosci 27:4519-4529.

Chang Q, Fischbach GD (2006) An acute effect of neuregulin $1 \beta$ to suppress $\alpha 7$-containing nicotinic acetylcholine receptors in hippocampal interneurons. J Neurosci 26:11295-11303.

Couey JJ, Meredith RM, Spijker S, Poorthuis RB, Smit AB, Brussaard AB, Mansvelder HD (2007) Distributed network actions by nicotine in- 
crease the threshold for spike-timing-dependent plasticity in prefrontal cortex. Neuron 54:73-87.

Dajas-Bailador F, Wonnacott S (2004) Nicotinic acetylcholine receptors and the regulation of neuronal signalling. Trends Pharmacol Sci $25: 317-324$

Falls DL (2003) Neuregulins: functions, forms, and signaling strategies. Exp Cell Res 284:14-30.

Ge S, Dani JA (2005) Nicotinic acetylcholine receptors at glutamate synapses facilitate long-term depression or potentiation. J Neurosci 25:6084-6091.

Gu Z, Jiang Q, Fu AK, Ip NY, Yan Z (2005) Regulation of NMDA receptors by neuregulin signaling in prefrontal cortex. J Neurosci 25:4974-4984.

Hancock ML, Canetta SE, Role LW, Talmage DA (2008) Presynaptic type III neuregulin1-ErbB signaling targets $\alpha 7$ nicotinic acetylcholine receptors to axons. J Cell Biol 181:511-521.

Harrison PJ, Weinberger DR (2005) Schizophrenia genes, gene expression, and neuropathology: on the matter of their convergence. Mol Psychiatry 10:40-68; image 5.

Huang YZ, Won S, Ali DW, Wang Q, Tanowitz M, Du QS, Pelkey KA, Yang DJ, Xiong WC, Salter MW, Mei L (2000) Regulation of neuregulin signaling by PSD-95 interacting with ErbB4 at CNS synapses. Neuron 26:443-455.

Jo YH, Wiedl D, Role LW (2005) Cholinergic modulation of appetiterelated synapses in mouse lateral hypothalamic slice. J Neurosci 25:11133-11144.

Kawai H, Zago W, Berg DK (2002) Nicotinic $\alpha 7$ receptor clusters on hippocampal GABAergic neurons: regulation by synaptic activity and neurotrophins. J Neurosci 22:7903-7912.

Kumari V, Postma P (2005) Nicotine use in schizophrenia: the self medication hypotheses. Neurosci Biobehav Rev 29:1021-1034.

Kwon OB, Longart M, Vullhorst D, Hoffman DA, Buonanno A (2005) Neuregulin-1 reverses long-term potentiation at CA1 hippocampal synapses. J Neurosci 25:9378-9383.

Leonard S, Gault J, Adams C, Breese CR, Rollins Y, Adler LE, Olincy A, Freedman R (1998) Nicotinic receptors, smoking and schizophrenia. Restor Neurol Neurosci 12:195-201.

Li B, Woo RS, Mei L, Malinow R (2007) The neuregulin-1 receptor erbB4 controls glutamatergic synapse maturation and plasticity. Neuron 54:583-597.

Lisman JE, Grace AA (2005) The hippocampal-VTA loop: controlling the entry of information into long-term memory. Neuron 46:703-713.

Liu Y, Ford B, Mann MA, Fischbach GD (2001) Neuregulins increase $\alpha 7$ nicotinic acetylcholine receptors and enhance excitatory synaptic trans- mission in GABAergic interneurons of the hippocampus. J Neurosci 21:5660-5669.

Mansvelder HD, van Aerde KI, Couey JJ, Brussaard AB (2006) Nicotinic modulation of neuronal networks: from receptors to cognition. Psychopharmacology (Berl) 184:292-305.

Massey KA, Zago WM, Berg DK (2006) BDNF up-regulates alpha7 nicotinic acetylcholine receptor levels on subpopulations of hippocampal interneurons. Mol Cell Neurosci 33:381-388.

Mathew SV, Law AJ, Lipska BK, Davila-Garcia MI, Zamora ED, Mitkus SN, Vakkalanka R, Straub RE, Weinberger DR, Kleinman JE, Hyde TM (2007) $\alpha 7$ nicotinic acetylcholine receptor mRNA expression and binding in postmortem human brain are associated with genetic variation in neuregulin 1. Hum Mol Genet 16:2921-2932.

McGehee DS, Heath MJ, Gelber S, Devay P, Role LW (1995) Nicotine enhancement of fast excitatory synaptic transmission in CNS by presynaptic receptors. Science 269:1692-1696.

Okada M, Corfas G (2004) Neuregulin1 downregulates postsynaptic GABAA receptors at the hippocampal inhibitory synapse. Hippocampus 14:337-344.

Ronesi J, Lovinger DM (2005) Induction of striatal long-term synaptic depression by moderate frequency activation of cortical afferents in rat. J Physiol (Lond) 562:245-256.

Stefansson H, Steinthorsdottir V, Thorgeirsson TE, Gulcher JR, Stefansson K (2004) Neuregulin 1 and schizophrenia. Ann Med 36:62-71.

Strand JE, Nybäck H (2005) Tobacco use in schizophrenia: a study of cotinine concentrations in the saliva of patients and controls. Eur Psychiatry 20:50-54

Wang Z, Kai L, Day M, Ronesi J, Yin HH, Ding J, Tkatch T, Lovinger DM, Surmeier DJ (2006) Dopaminergic control of corticostriatal long-term synaptic depression in medium spiny neurons is mediated by cholinergic interneurons. Neuron 50:443-452.

Wolpowitz D, Mason TB, Dietrich P, Mendelsohn M, Talmage DA, Role LW (2000) Cysteine-rich domain isoforms of the neuregulin-1 gene are required for maintenance of peripheral synapses. Neuron 25:79-91.

Yang X, Kuo Y, Devay P, Yu C, Role L (1998) A cysteine-rich isoform of neuregulin controls the level of expression of neuronal nicotinic receptor channels during synaptogenesis. Neuron 20:255-270.

Zornoza T, Cano-Cebrián MJ, Miquel M, Aragón C, Polache A, Granero L (2005) Hippocampal dopamine receptors modulate the motor activation and the increase in dopamine levels in the rat nucleus accumbens evoked by chemical stimulation of the ventral hippocampus. Neuropsychopharmacology 30:843-852. 